\title{
THE EFFECT OF AEROBIC GYMNASTIC TRAINING AT MENSTRUAL CYCLE PHASE AND PERCEPTION ON MAXIMUM AEROBIC CAPACITY
}

\author{
Umar $^{1}$ \\ umarmardesia@gmail.com \\ Sport Science Faculty \\ Universitas Negeri Padang \\ Padang, West Sumatera
}

\begin{abstract}
This study was intended to investigate the effect of aerobic gymnastic training at the menstrual cycle phase and perceptions of female students of Sport Science Faculty of State University of Padang on maximum aerobic capacity. The research was conducted using repeated factorial design $2 \times 3$. Aerobic gymnastic training was a treatment given to the menstrual cycle phase as independent variables, perception as the attribute variable, and the maximum aerobic capacity as the dependent variable. 40 students were taken by using purposive sampling technique as the samples from 170 female students enrolled at 2010/2011 academic year. The data of menstrual cycle phase and perception were collected by using questionnaires while the data of maximum aerobic capacity were taken by using MSFT (beep test). The data of maximum aerobic capacity were then analyzed using by inferential statistics ANOVA 2 × 3 two paths .The data analysis and interpretation indicate that: (1) as the whole, there is a significant difference of the effect of aerobic gymnastic training during premenstrual, menstrual, and postmenstrual phases on the maximum aerobic capacity; (2) there is an interaction between the effects of aerobic gymnastic training during the menstrual phases and the perception on maximum aerobic capacity; (3) there is no significant effect of aerobic gymnastic training during premenstrual and menstrual phases of the students whose positive perception on maximum aerobic capacity; (4) there is a significant effect of aerobic gymnastic training during premenstrual and postmenstrual phases of the female students whose positive perception on maximum aerobic capacity; (5) there is no significant effect of aerobic gymnastic training during menstrual and postmenstrual phases of the female students whose positive perception on maximum aerobic capacity; (6) there is a significant effect of aerobic gymnastic training during premenstrual and menstrual phases of the female students whose negative perception on maximum aerobic capacity; (7) there is no significant effect of aerobic gymnastic training during premenstrual and postmenstrual phases of the female students whose positive perception on maximum aerobic capacity; and (8) there is a significant effect of aerobic gymnastic training during menstrual and postmenstrual phases of the female students whose negative perception on maximum aerobic capacity. The findings imply that the lowness of maximum aerobic capacity of the students during menstruation is not mainly due to the menstruation itself but more to the negative perception during on the maximum aerobic capacity. Therefore, the teachers, lecturers, and trainers are expected to provide the female students (at any levels of education) with better explanation on the menstrual cycle phases and their effects on physical activities (sports)
\end{abstract}

Keywords: maximum aerobic capacity, aerobic gymnastic training, phases of the menstrual cycle, perception. 


\section{Introduction}

Development is still under heavy conducted by the government, including the development in the field of sports, is aimed at improving the quality of human resources (HR). Improving the quality of human resources is a sport that is not only limited to the improved quality of health and physical fitness, but more related to the mental and spiritual formation, and encourage sportsmanship, which in turn can deliver outstanding athlete who was able to raise the dignity of the nation.

To deliver outstanding athlete, not an easy task, but it requires careful planning, as well as a tiered formation. Coaching is done through exercise is one of them, since one purpose of the exercise is to help athletes improve their skills and accomplishments, especially on the four aspects such as engineering, physical condition, tactics and strategies, as well as mental. One important aspect that should be owned by an athlete, the physical condition is a fundamental aspect to support other aspects. Elements of the physical conditions such as strength, speed, endurance, flexibility, agility, balance and coordination. Elements of the physical conditions which must be owned by an athlete, it depends on the sport that they do, because each sport has it's own characteristics.

In endurance sports such as distance running medium to long distances, swimming to 100 meters, the branches of martial arts and others, endurance a major physical component to have, especially endurance aerobic, because to be able to perform activities within relatively long, required endurance_aerobics. endurance aerobics, the body's ability to carry out activities for a long time without experiencing fatigue, which means using aerobic energy supply.

High or low levels of aerobic endurance, will be affected by high or low levels of $\mathrm{VO}_{2} \max$ known as maximal aerobic capacity. The level of maximal aerobic capacity is affected by the organic components such as the lungs as a supplier of oxygen, as the heart pumps blood to all tissues of the body, the quality of the blood vessels that will circulate blood throughout the body, the quality of the blood (hemoglobin) that carries oxygen and carbon dioxide, and skeletal muscle that will consume oxygen for aerobic energy metabolism, resulting in energy for work cells, including muscle cells.

Maximal aerobic capacity $\left(\mathrm{VO}_{2} \max \right)$ is high, it is not only required by athletes during training and match him, but also needed at the time they do a recovery (recovery). Defeat is often experienced by an athlete in a game, one of which is caused by low their maximum aerobic capacity, this can be seen in every game as a branch of martial. In general, athletes perform excellent and ferocious round (rounds) early, but the next round, they are especially endurance tendency ability starts to decline, it is proof that they are not supported by maximal aerobic capacity $\left(\mathrm{VO}_{2} \mathrm{max}\right)$ is high, so that the recovery process (recovery) is not running perfectly.

Specialized in women, the problem that often occurs is always not joining the sports activities, both in the teaching and learning process in school and campus, or missed training or match when they menstruate. Their reasoning, that menstruating means the body is sick, so they should not do physical activities, including sports. It is more based on their negative perceptions about menstruation that they got from their parents. In case, according to some research results were reported earlier breaking the world record, in case they're menstruating.

This study wanted to see if there are differences in physical abilities (maximal aerobic capacity) if given training in the premenstrual phase, menstruation and postmenstrual on two groups of samples that have a positive perception and negative perception to the phase of the menstrual cycle. Hopefully with the results of this study, can provide insight as well as reassuring

to the students, female students, athletes, and sports teachers and coaches, to the actual conditions at the time of a woman who is menstruating. 


\section{Literature Review}

As explained earlier, that endurance (aerobic endurance) is one component of a physical condition that is needed, especially for branches of sports which require endurance, while the highlow aerobics endurance influenced by the level of maximal aerobic capacity $\left(\mathrm{VO}_{2} \mathrm{max}\right)$. High maximal aerobic capacity, not only required during training and matches, but is also required at the time of recovery (recovery).

\section{Maximal Aerobic Capacity}

According to Elizabeth Quin that ; ' $\mathrm{VO}_{2} \mathrm{max}$, or maximal oxygen uptake, is one factor that can determine an athlete's capacity to perform sustained exercise and is linked to aerobic endurance ". $\mathrm{VO}_{2}$ max refers to the maximum amount of oxygen that can be utilized by an individual during maximal or exhaustive exercise. It is measured as milliliters of oxygen used in one minute per kilogram of body weight, is generally regarded as the best indicator of cardiorespiratory fitness and aerobic endurance.

Meanwhile, according to Churchill that; "maximal oxygen uptake ( $\left.\mathrm{V}_{2} \mathrm{max}\right)$ can be defined as the highest rate at which oxygen can be extracted, transported and consumed for aerobic ATP synthesis process. Typically, maximal aerobic capacity expressed in milliliters of oxygen per kilogram of body weight per unit time (ie mL.kg-1.min-1.) '. On the other hand Mackenzie said: " $\mathrm{VO}_{2} \mathrm{max}$ is the maximum amount of oxygen in millilitres, one can use in one minute per kilogram of body weight. Those who are fit have higher $\mathrm{VO}_{2} \mathrm{max}$ values and can exercise more intensely than those who are not as well conditioned ". Numerous studies show that capacity strongly related to maximal aerobic performance requires endurance. It is like the words of T. Meyer and his colleagues that: "Maximal oxygen uptake $\left(\mathrm{VO}_{2} \mathrm{max}\right)$ is a parameter that is commonly used to characterize endurance capacity".

This is similar to what was said by Elizabeth Quin that: "This measurement is generally considered the best indicator of an athlete's cardiovascular fitness and aerobic endurance. Theoretically, the more oxygen you can use during high level exercise, the more ATP (energy) you can produce. Often this is the case with elite endurance athletes who typically have very high $\mathrm{VO}_{2}$ max values ". The level of maximal aerobic capacity is influenced by several factors such as the ability of the heart to pump blood throughout the body to function, the ability of lung function to take oxygen from the air outside, the quality of the blood (hemoglobin), which functions bind and carry oxygen to all the cells, blood vessels that circulate blood throughout the body, and the ability of skeletal muscle to be put on oxygen for metabolism (oxidation), resulting in a lot of energy to support long physical activity (endurance). In other words, one maximal aerobic capacity is influenced by aerobic fitness. It is like Melvin H. Williams said that;"Aerobic fitness is a complex component of physical fitness. It involves the interaction of numerous physiological processes in the cardiovascular, respiratory, and muscular systems, Including the capacity of the lungs to take up oxygen, the capacity of the blood in the lungs to pick up oxygen, the capacity of the heart to pump this oxygenated blood to the muscle tissues, and the capacity of the tissues to extract the oxygen from the blood and use it to generate energy in the form of ATP via the oxygen system ". Because maximal aerobic capacity is needed, especially for sports branches demanded endurance high, then the maximal aerobic capacity should be increased. The increase in maximal aerobic capacity can be done in various ways, one of which is to do the exercises. Among the various forms of exercise, one of them is aerobic exercise (aerobic gymnastic training). 


\section{Aerobic Gymnastic Training}

According to Bompa: "Exercise is a sports activities are carried out systematically in a long time and lead to physiological characteristics and physicologic to achieve predetermined goals. Meanwhile Hairy said that: "Exercise is physical activity planned, structured, repetitive and purposeful, the thing to improve or maintain physical fitness level. Aerobics pioneer was Dr.. Kenneth Cooper in 1960 said that: an aerobic exercise that is based on the concept of musical rhythms and movements that are irregular, so the body can pump oxygen and increase heart rate. Aerobic exercise is any activity or exercise that demands more oxygen to extend the time and force the body to repair the system. This is similar to an excerpt from the bulletin Total Fitness Training Centre that: "Gymnastics is a form of aerobic exercise or movement performed repeatedly and use the large muscles of the body at least 15 minutes and requires oxygen as an energy source. On the other hand, as quoted by Dukes University, in http:// cantiksehat-cerdas.wordpress.com that; Exercise during menstruation burn fat faster, because it is advisable if you want to quickly trim, doing aerobic exercise from the first day to get your period until the last day. Then start practicing again five to seven days after the fertile period. Exercising in those moments will make you fat burns faster than other days.

Meanwhile, according to Berawi that: Aerobic Gymnastics is believed to minimize menstrual pain in some way, can suppress the production of prostaglandins, responding and adapting to regulatory hormones. Moreover, it makes the body produce endorphins, a chemical reaction that serves as a natural pain reliever in the pelvis, the achievement ratio of estroneestradiol may lower endometrial proliferation, and blood circulation in the uterus. Berawi further said that: Aerobic Exercise helps in sweat and reduce the accumulation of fluid in the body, which is increased when women before menstruation. In addition, by doing aerobic exercise helps maintain mental health effects on serotonin-dopamine regulation, relieve anxiety, stress and even the feeling changes. With the mechanism, aerobics considered to relieve menstrual pain.

\section{Menstrual Cycle Phase}

According to Guyton that: "The menstrual cycle is also known as female sexual cycle, the normal female reproductive period marked by monthly rhythmical changes in the speed of female hormones secretion and changes in sexual organs themselves. Meanwhile, Salomon said that: "In a woman's normal menstrual cycle lasted for 28 days with details, 5 days of menstruation (bleeding), 8 days preovulation phase, ovulation phase 1 day and 14-days phase postovulation". In this regard, Vander said that: "The first day of menstrual bleeding, and the rest of the menstrual period is known as the menstrual phase, which is generally about 3 to 5 days in 28 cycles of a typical day. While Fox split the phase of the menstrual cycle into three phases, namely; premenstrual phase, menstrual phase, and postmenstrual phase.

Premenstrual phase is the phase before a woman was bleeding (bleeding), or just before menstruation. According to Fox that; "premenstrual phase is 7 days after ovulation". To determine the time of ovulation in a woman according to Salomon was: "Ovulation occurs on day 14 of the first day of bleeding. So when a woman menstruates on December 1st, then ovulation occurs on the 14th. While premenstrual is 7 days after the date of the 14th of 21 . In the days before menstruation (premenstrual), most women will experience what is called PMS (Premenstrual Syndrome) or abbreviated as PMS. According to Devi that: "PMS is that symptoms felt by a woman on one or two weeks before menstruation. The symptoms are a collection of physical and psychological symptoms associated with the occurrence of a woman's menstrual cycle. 
According to studies conducted by the doctors, the symptoms of PMS is divided into two: physical and psychological symptoms. Physical symptoms include abdominal bloating, breast swelling and tenderness, fatigue, pelvic pain, back pain and muscle and headaches. While the psychological symptoms include irritability, emotional, irritable, crying easily, trouble concentrating, forgetfulness and depression. Generally, improved emotional state at the time of premenstrual influenced by the production of hormones in the brain, especially or other types of serotonin hormone that controls emotional stability. This process causes emotional turmoil as part of PMS (premenstrual syndrome) are beginning to be felt 7-10 days before menstruation.

Menstrual phase is the release of the uterine lining (endometrium) accompanied by bleeding in or a phase of hemorrhage (bleeding) experienced by a woman, because the ovum is not fertilized and occurs every month except during pregnancy. Meanwhile Ganong said: "menstruation is the periodic vaginal bleeding that occurs with the release of the uterine mucosa. On the other hand, Guyton said that: "during the period progresses, blood coming out of approximately $35 \mathrm{ml}$ with serous fluid as much as $35 \mathrm{ml}$, which lasts for 3-7 days with a cycle of approximately 28 days.

In the menstrual phase, will likely impact the ability of women to perform various activities, it is due to the reduction of iron in the red blood cells. According EHN, Calmark in Fox that: "Women are more susceptible to decreased iron than men because women menstruate, especially in women athletes who will further affect the performance, because iron is needed during physical exercise. Several studies report that a reduction in iron as a result of menstruation will affect the working capacity, especially endurance of aerobics. However, the effect of individual nature. Some women will experience performance degradation during menstruation, but for most other women do not have a significant effect.

Postmenstrual phase is a phase after a woman menstruating. Phase postmenstrual peak occurs at 13 days after the first bleeding. If a woman experiences bleeding begins on 1, then the phase postmenstrual is on the 13th. For more details can be seen in the figure below, which shows the phase of the menstrual cycle, with the release of a variety of hormones that affect other hormones, in a matter of days (date).

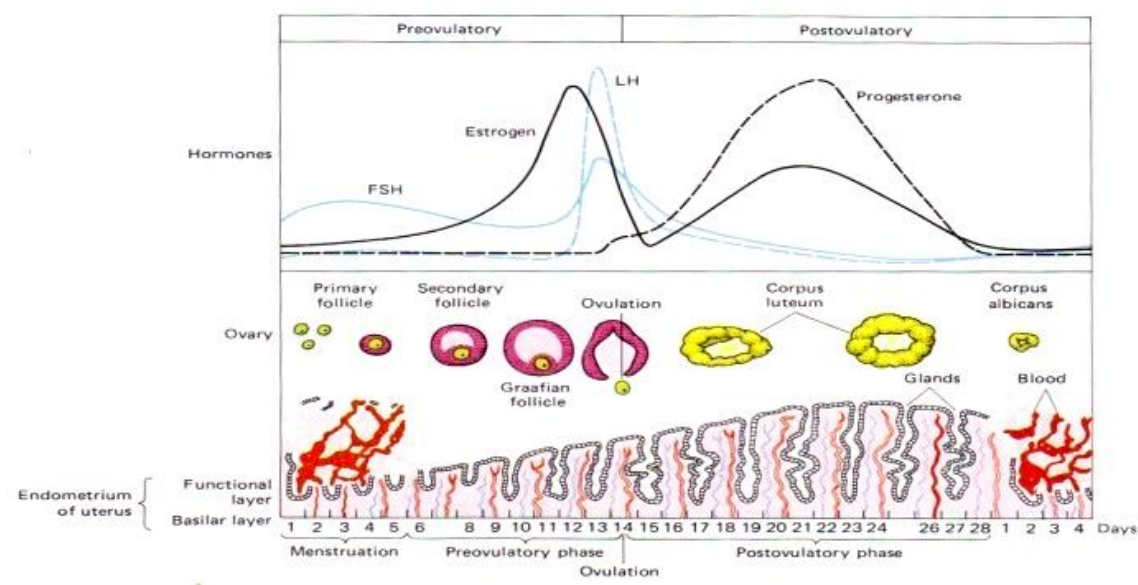

Picture 1. Menstrual Cycle Phase

Source ; Salomon E.P. Human Anatomy and Physiology, 1990

Based on the picture above can be explained that: if a woman has a menstrual period menstruation begins on June 1 and the end of the 5th, the phase of the production of estrogen and progesterone to stop, but there is little hormone FSH. Once the period expires, the hormone estrogen begin to be issued to a peak on the 12th and continued to decline to the lowest on the 15th 
after ovulation. Instead issued progesterone will culminate on December 21, but there are still small amounts of the hormone estrogen. It can be concluded that: the premenstrual phase (postovulatory phase) there is a little progesterone hormone estrogen. In the absence of menstrual phase estrogen and progesterone but there are hormone FSH (folicle stimulating hormone). While postmenstrual phase (preovulatory phase) contained estrogen and LH (Luteinizing Hormone) in large quantities without progesterone.

The hormone estrogen is responsible for accelerating the growth of a woman's body, and then play developing uterine, ovarian and other reproductive system, so the body is ready to support the pregnancy. In addition, the hormone estrogen stimulates the growth of the sex organs of woman, regulate the menstrual cycle, preventing the symptoms of menopause such as hot flushes (hot flashes in areas of the upper body and mood disorders). With regard to the other functions of the hormone estrogen, as quoted http://digilib.unsri.ac.id/download/ that another function of the hormone estrogen is: 1. Affect other hormones; (a). suppress the production of hormones FSH and LH secretion causes, (b). stimulate growth in the ovary follikel, despite the lack of FSH. 2. induce proliferation of both endometrial glands and stroma, 3. change the infantile uterus becomes mature, 4. stimulate muscle growth and increase muscle activity fallopian tube, 5 . cervix uteri becomes soft, ostium uteri open and growing with mucus, watery, and alkaline $\mathrm{pH}$ increased aselluler so easily passed spermatozoa, 6 . led to the growth of most lobuli mamma gland alveoli and ducts. Meanwhile, the hormone progesterone regulates the menstrual cycle, breast tissue develops, prepares the uterus during pregnancy, protect postmenopausal women against endometrial cancer.

How is the performance of female athletes during menstruation?. According to Fox that the influence of menstruation on performance (performance) is individualized. So is the case for the other phases of the menstrual cycle (premenstrual and postmenstrual). Both phases, although any effect on performance, but it is individual. It is as reported by Fox that examines the influence of menstrual cycle on metabolic and cardiovascular response in athletes and non-athletes. The results of these studies reported that: "in women who are menstruating athletes capacity their maximal aerobic higher than in women who are not athletes.

\section{Perception}

According Marliani that; perception comes from the English that perception, that the perception of something or express an understanding of refined intellect, that is related to the perception of the external factors that responded through the five senses, memory, and power of the soul. In an effort to admit there is a perception of something, deny, understand something, attributed the understanding of each other, decide and draw conclusions. While Branca noted that: "Perceptions are orientative reactions to stimuli". Meanwhile, Polak states that: "A percept is an organized totality rather than the sum total of individual sensory experiences. In perception, an individual first gains a general impression of the outline of on object or situation, (which is) the percepts quality of organized totality". In the process of individual perceptions are required to provide an assessment of an object that can be either positive / negative, happy or unhappy, and so on. With the perception of attitude will be formed, which is a stable tendency to behave or act in a certain way in certain situations anyway. Meanwhile Dariyo said, In theory often expressed that attitude is a predisposition (determinants) that elicits the behavior appropriate to the position. Attitudes to grow, starting from the knowledge perceived as something good (positive) or bad (negative). 
Meanwhile, if the performance capabilities associated with perceptions of the menstrual phase. According Dariyo that: 'In the perception of the individual is required to provide an assessment of an object that can be either positive / negative, happy or unhappy, and so on. With the perception of attitude will be formed, which is a stable tendency to behave or act in a certain way in certain situations anyway. With that can be concluded that: if someone were of a negative perception of something, then he does not want to do or if they do out of necessity.

\section{Methodology}

This study aims to determine the effect of differences in aerobic exercise on the menstrual cycle phase and perception, the maximal aerobic capacity. The research was conducted in the laboratory and the Sports Hall of the Faculty of Sport Science State University of Padang. The data collection process research done in 2 (two) main stages. The first phase of data collection on the status and perception of the sample period for 2 months. The second stage is the implementation of this exercise aerobic exercise 18 times, ( 6 times exercise on premenstrual phase, 6 times the exercise on the menstrual phase and 6 times postmenstrual training phase) with a time of 1.5 months (first menstrual cycle). The stages of the research include: 1) Pre-survey, 2) test instrument, 3) Reporting the results of testing instruments, 4) Data collection menstrual status and perception, 5) Provision of treatment, 6) Maximal Aerobic Capacity of data collection, 7) Analysis of data, and 8) Writing a research reports.

The method used in this study is quasi-experimental methods (quasi experiment). The study consisted of three independent variables namely: premenstrual phase, menstrual phase and the of postmenstrual phase. In the third phase of menstruation is given the same treatment that aerobic exercise. Variable attribute consists of two, namely: perception of positive and negative perceptions. While the dependent variable is the maximal aerobic capacity.

The research design was used within subject factorial design or redesign $2 \times 3$, because the sample of 20 people will represent a positive perception in every phase of menstruation (premenstrual phase, and the phase of the menstrual phase postmenstrual), as well as on a sample consisting of a negative perception 20 people sampled. plan is used because there are three groups of the independent variables (premenstrual, menstrual and postmenstrual) given the same treatment ie aerobics. For more details about the design of this study can be seen in the following table;

Table 1. Research Design

\begin{tabular}{|l|c|c|c|}
\hline \multirow{2}{*}{$\begin{array}{c}\text { Menstrual } \\
\text { Cycle } \\
\text { Perception (A) }\end{array}$} & \multicolumn{3}{|c|}{ Aerobic Gymnastic Training } \\
\cline { 2 - 4 } & $\begin{array}{c}\text { Premenstrual } \\
\left(\mathrm{A}_{1}\right)\end{array}$ & $\begin{array}{c}\text { Menstrual } \\
\left(\mathrm{A}_{2}\right)\end{array}$ & $\begin{array}{c}\text { Postmenstrual } \\
\left(\mathrm{A}_{3}\right)\end{array}$ \\
\hline Positive $\left(\mathrm{B}_{1}\right)$ & $\mathrm{A}_{1} \mathrm{~B}_{1}$ & $\mathrm{~A}_{2} \mathrm{~B}_{1}$ & $\mathrm{~A}_{3} \mathrm{~B}_{1}$ \\
\hline Negative $\left(\mathrm{B}_{2}\right)$ & $\mathrm{A}_{1} \mathrm{~B}_{2}$ & $\mathrm{~A}_{2} \mathrm{~B}_{2}$ & $\mathrm{~A}_{3} \mathrm{~B}_{2}$ \\
\hline
\end{tabular}

The population in this study, is a student FIK UNP as the target population (target population). While the population of affordable (accessible population) is a student armed UNP FIK 2010/2011 are listed in the first half of July-December 2010/2011, as many as 170 people. In 
a population given a questionnaire to obtain data on the phase of the menstrual cycle and their perceptions of the menstrual cycle. Based on the spread of the questionnaire, the sample taken as many as 40 people with purposive sampling (sampling with a specific purpose). Specific purpose here is, choosing a college student sample had normal or irregular menstrual cycles. That is, the student whose menstrual cycles are not normal or irregular such as delayed menstruation or menstrual date forward (faster than the previous date), excessive pain during menstruation, menstrual period more than once a month, or menstruation does not come in a month, then they are not included as a sample in this study. Taking a sample of 40 people was based on the results of a questionnaire given to the population about menstrual status and their perceptions. Furthermore, of the 40 people, the samples were divided into 2 groups of 20 people to fill in cells that have a positive perception (B1), and 20 people to fill the cells that have a negative perception (B2), as can be seen in the table below;

Table 2. Sample Grouping Research

\begin{tabular}{|c|c|c|c|c|}
\hline \multirow{2}{*}{$\begin{array}{c}\text { Menstrual } \\
\text { Cycle } \\
\text { (A) }\end{array}$} & \multicolumn{3}{|c|}{ Aerobic Gymnastic Training } & \\
\cline { 2 - 4 } & $\begin{array}{c}\text { Premenstrual } \\
\text { Perception (B) }\end{array}$ & $\begin{array}{c}\text { Menstrual } \\
\text { (A2) }\end{array}$ & $\begin{array}{c}\text { Postmenstrual } \\
\text { (A3) }\end{array}$ & total \\
\hline Positive $\left(\mathrm{B}_{1}\right)$ & 20 & 20 & 20 & 60 \\
\hline Negative $\left(\mathrm{B}_{2}\right)$ & 20 & 20 & 20 & 60 \\
\hline Total & 40 & 40 & 40 & 120 \\
\hline
\end{tabular}

Data collection techniques used in this research is based on variables that exist. The collection of data for the dependent variable (maximal aerobic capacity) using test MSFT (Beep Test). While collecting data on the perception and status of the sample period, using a questionnaire. Data analysis using descriptive statistics serve to describe the data, and inferential statistics using analysis of variance (ANOVA) two-way factorial design with 2 X 3 at a significance level of $\alpha=$ 0.05. Then followed by Tukey test. However, prior to the ANOVA test, the first test performed with Kolmogorof Smirnof normality and homogeneity of variance test with Bartlett test.

\section{Results}

Hypothesis testing was done by using ANOVA analysis of the two lines, then, if there is interaction between the phases of the menstrual cycle and the perception of maximal aerobic capacity, then followed by Tukey test. ANOVA analysis purposes to determine the effect of two lines of independent variables on the experimental results (main effect) and to determine the effect of the interaction (interaction effect). The primary effect in this study were: (1) differences in the effect of aerobic gymnastic training on the menstrual cycle phase and perceptions of maximal aerobic capacity, (2) differences in maximal aerobic capacity for students who have a positive perception and negative premenstrual phase, and the phase of the menstrual phase post menstrual. While the effect of interaction is the effect of the combination of the phase of the menstrual cycle and the perception of maximal aerobic capacity. 
Furthermore, the results of data analysis performed using ANOVA and summarized in Table 3, below;

Table 3. Calculation Result Summary Anova 2 x 3

\begin{tabular}{|l|r|r|r|r|r|r|r|}
\hline \multicolumn{1}{|c|}{ Variance } & \multicolumn{1}{c|}{ JK } & \multicolumn{1}{c|}{ df } & \multicolumn{1}{c|}{ RJK } & \multicolumn{1}{c|}{ Fh } & \multicolumn{1}{c|}{ p } & $\alpha=0,05$ & $\alpha=0,01$ \\
\hline Between Groups & 169,584 & 2 & 84,792 & 9,746 &, 000 & 0,05 & 0,01 \\
\hline Interaction A X B X C & 134,027 & 2 & 67,014 & 27,866 &, 000 & 0,05 & 0,01 \\
\hline Within Groups & 1017,935 & 117 & 4,112 & & & & \\
\hline Total & 1187,519 & 119 & & & & & \\
\hline
\end{tabular}
follows:

Based on the results of the calculation Anova analysis, hypothesis testing is done as

Overall there is a difference between the phases of maximal aerobic capacity premenstrual, menstrual and post menstrual after aerobic exercise.

The results of calculations using ANOVA two lines indicate that the value $p=0,00<\alpha=0,05$ and $\alpha=0,01$. Meaning; Ho stated that overall there was no difference between the phase of maximal aerobic capacity premenstrual, menstrual and post menstrual after aerobic exercise is rejected. While Ha proposed in this study, namely: overall there is a difference between the phases of maximal aerobic capacity premenstrual, menstrual and post menstrual after aerobic exercise accepted as true empirically.

The results showed that: the low maximal aerobic capacity during menstruation is not caused by menstrual phase itself, but rather due to the negative perception towards menstruation. This is evidenced by the results of measurements of maximal aerobic capacity during menstruation was higher in samples that have a positive perception towards menstruation. It can be concluded that: in fact there is no obstacle for a person to physical activity, including exercise performs during menstruating. Note that at the time of menstruation did not experience pain (amenorhea), or other disturbances such as nausea, dizziness and weak body.

\section{Conclusion}

The conclusion of this study are as follows: 1) as the whole, there is a significant difference of the effect of aerobic gymnastic training during premenstrual, menstrual, and postmenstrual phases on the maximum aerobic capacity. 2) There is an interaction effect between aerobic exercise on the menstrual cycle phase and perceptions of maximal aerobic capacity. $p=0.00<\alpha=0.05 .3$ ) There were no differences in maximal aerobic capacity of female college students have a positive perception among premenstrual and menstrual phases, namely, $p=0.533>\alpha=0.05$. 4) the maximal aerobic capacity of female college students have a positive perception, lower the premenstrual phase of the phase postmenstrual, after doing aerobic exercise. $p=0.007<\alpha=0.05$. 5 ) There is no difference in the maximal aerobic capacity of female college students have a positive perception between menstrual phase and postmenstrual. $p=0.428>\alpha=0.05$. 6) the maximal aerobic capacity of female college students have a negative perception, higher premenstrual phase of the menstrual phase, after doing aerobic exercise. $p=0.00<\alpha=0.05$. 7) There is no difference in the maximal aerobic capacity of female college students have a negative perception among the premenstrual phase and postmenstrual $p=0.473>\alpha=0.05$. 8) the maximal aerobic capacity of female college students have a negative perception, lower in the menstrual phase of the phase postmenstrual, after doing aerobic exercise. $\mathrm{p}=0.00<\alpha=0.05$. 


\section{References}

Berawi K. N. (2011). http://www.radarlampung.co.id/read/bandarlampung/metropolis/32981aerobik-redakan-nyeri-haid, Radar Lampung.

Bompa, T.O. Haff, G.G. (2009). Periodization, Theory and Methodology of Training. Fifth ed. New York. Human Kinetics.

Branca, http://www.banjarmasinpost.co.id/read/artikel/22720/olahraga-saat-menstruasi

Dariyo A., (2004). Psikologi Perkembangan Remaja, Bogor: GHALIA INDONESIA.

Devi Nirmala. (2012). Gizi Saat Sindrom Menstruasi. Jakarta, PT. Buana Ilmu Populer Kelompok Gramedia.

Dukes University, (2010) http://cantiksehatcerdas.wordpress.com., ,

Elizabeth Quinn. (2011) What Is VO2 max. http://sportsmedicine.about.com/od/anatomyand physiology/a/VO2_max.htm.

Fox, E.L. Bowers, R.W. Foss, M.L. (1988). The Physiological Basis of Physical Education and Athletics, Fourth Ed. New York: W.B. Saunders Company.

Ganong, W.F. (1989). Review of Medical Physiology, Fourteenth Ed. San Francisco: Prentice-Hall International Inc.

Guyton, A.C. (2010). Texbook of Medical Physiology, Philadelphia: W.B. Saunders Company.

Hairy J. (2010). Dasar-dasar Kesehatan Olahraga. Jakatra - Univerasitas Terbuka.

Mackenzie B. (2005).101 Performance Evaluation Tests, London: Electric Word plc.

Margaret R., Sally H., Veronica R., (2005). The Abnormal Menstrual Cycle, London: Taylor \& Francis Group.

Marliany Rosleny.( 2010). Psikologi Umum, Bandung: CV Pustaka Setia.

Polak, (2008). http://lifestyle.okezone.com/index.php/ReadStory/2008.

Salomon, E.P.(1990). Human Anatomy and Physiology, Second Ed. Philadelphia: Saunders College Publishing.

T. Meyer J.-P. Welter J. Scharhag W. Kindermann. (2003). Maximal oxygen uptake during field running does not exceed that measured during treadmill exercise. Eur J Appl Physiol. pp. 88: 387-389. 
Vander Artur J, James H. Sherman dan Dhorothy S. Luciano. (2001). Human Physiology The Mechanism of Body. New York: The McGraw-Hill Company. 